\title{
REKAYASA SISTEM MONITORING DAN ANALISIS TEMPERATUR MOTOR LISTRIK BERBASIS KOMPUTER
}

\author{
TUGINO \\ Jurusan Teknik Elektro Sekolah Tinggi Teknologi Nasional Yogyakarta \\ Jl. Babarsari CT Depok Sleman Yogyakarta Telp 485390 \\ E-mail; tugino@sttnas.ac.id
}

\begin{abstract}
Abstrak
REKAYASA SISTEM MONITORING DAN ANALISIS TEMPERATUR MOTOR LISTRIK BERBASIS KOMPUTER. Kerusakan motor listrik dapat dideteksi secara dini dari temperaturnya. Temperatur motor listrik yang abnormal yang terjadi disebabkan karena adanya kerusakan diantaranya kerusakan pada bearing, ketidak seimbangan beban, misalignment, kegagalan isolasi pada lilitan motor dan lain-lain. Penelitian ini bertujuan untuk merancang alat monitoring dan analisis temperatur motor listrik berbasis komputer. Penelitian ini dapat digunakan untuk membantu mendeteksi secara dini terjadinya kerusakan awal pada motor listrik yang dapat menyebabkan pola temperatur dan amplitudo yang cenderung naik, sehingga dapat medukung program pemeliharaan pada motor listrik. Alat tersebut terdiri dari tiga sensor temperatur yaitu sensor temperatur A, B dan C, penguat sensor menggunakan Opamp, ADC, kartu antarmuka ke komputer dengan komunikasi serial serta komputer yang diprogram dengan bahasa Borland Delphi. Setelah melakukan pengujian maka didapat bahwa alat telah dapat bekerja sesuai dengan yang diinginkan. Pengujian pola temperatur motor yang dilakukan diantarannya saat motor tanpa beban, motor berbeban seimbang dan berbeban tidak seimbang. Pada pengujian terlihat bahwa monitoring temperatur akan dapat terdeteksi jika terdapat kejanggalan pada motor yang akan menyebabkan kenaikan temperatur, jika kenaikan tersebut melebihi batas yang telah diseting maka alat akan menyalakan alarm dan lampu tanda bahaya.
\end{abstract}

Kata kunci:Monitoring, temperatur, motor, komputer

\begin{abstract}
MONITOR SYSTEM AND TEMPERATURE ANALYSIS OF ELECTRICAL MOTOR BASED ON COMPUTER. Electrical motor damage can be detected prematurely from its temperature. The abnormal temperature occurred by damaging on bearing, load unbalancing, misalignment, isolation failure on motor coil, etc. The purpose of this research is for designing monitoring device and electrical motor temperature analyzer based on computer. This research can be used for helping on detecting prematurely the occur of early damaging on electrical motor that caused temperature pattern and amplitude that incline up, then it can support the motor maintenance program. The device are consist of three temperature sensor (A, B, and
\end{abstract}


C temperature), sensor amplifying based on op-amp, ADC, computer interface card using serial communication, and a computer that programmed using Borland Delphi. After performing test, this research has a result that is the device can work appropriate. The testing of motor temperature pattern is performed on unloaded motor, balancing loaded motor, and unbalancing loaded motor. On the testing is show that monitoring of temperature can detect an improper condition in motor that caused by raising temperature. If its increment over the limit that have been set, then the device will turn on alarm and caution lamp as a dangerous sign.

Keywords : Monitoring, temperature, motor, computer

\section{PENDAHULUAN}

Motor listrik sangat diperlukan untuk kalangan industri maupun rumah tangga, pemakaiannya meliputi banyak penggunaan seperti untuk penggerak, conveyor, pompa, dan lain-lain. Kebanyakan pengguna motor jarang memperhatikan tentang penyebab terjadinya kerusakan pada motor tersebut. Adakalanya pengguna tidak mengetahui sebab-sebab kerusakan dari motor tersebut. Sebenarnya kerusakan motor dapat dideteksi secara dini dari temperaturnya. Temperatur motor listrik yang abnormal yang terjadi disebabkan karena adanya kerusakan diantaranya kerusakan pada bearing, ketidak seimbangan beban, misalignment, kegagalan isolasi pada lilitan motor dan lain-lain. Seorang ahli listrik dapat mendeteksi jenis dan tingkat kerusakan motor listrik dengan sinyal temperaturnya seperti layaknya seorang dokter mendeteksi penyakit pasien dengan menganalisa denyut/detak jantung. Pendeteksian dini terhadap kerusakan motor dengan melihat pola temperatur motor yang terjadi dapat mendukung program predictive maintenance yang saat ini digalakkan oleh kalangan industri ${ }^{[1]}$.

Penelitian ini juga dimaksudkan untuk memperoleh suatu alternatif baru rekayasa sistem monitoring dan analisis temperatur motor listrik yang menggunakan basis komputer dengan unjuk kerja yang baik tetapi dengan biaya yang lebih murah dan bahan tersedia di pasaran Indonesia. Selain itu untuk memperkecil faktor ketergantungan alat monitoring temperatur yang berasal dari import yang cenderung harganya mahal dan susah didapat ${ }^{[2]}$.

\section{DASAR TEORI}

Dalam kondisi kerja normal, temperatur motor yang pada kondisi baik cenderung konstan dan saat terjadi ketidakberesan karena pengaruh elektrik atau mekanik maka akan terjadi kenaikan temperatur.

Pada beberapa tipe motor, terdapat batasan kenaikan temperatur maksimal yang boleh diijinkan, namun apabila terjadi kenaikan yang diluar diijinkan motor, harus segera berhenti atau terlepas dari sumber agar 
kerusakan yang lebih fatal dapat dihindari. Pada Tabel 1 diperlihatkan kelas isolasi motor yang diijinkan ${ }^{[3]}$.

Tabel 1. Kelas isolasi Motor

\begin{tabular}{cc}
\hline Kelas isolasi & $\begin{array}{c}\text { Temperatur lilitan maksimum } \\
(\mathrm{C})\end{array}$ \\
\hline $\mathrm{A}$ & $105^{\circ}$ \\
$\mathrm{B}^{*}$ & $130^{\circ}$ \\
$\mathrm{F}^{*}$ & $155^{\circ}$ \\
$\mathrm{H}$ & $180^{\circ}$ \\
$*$ Motor yang sering digunakan di Industri \\
\hline
\end{tabular}

Rumusan temperatur lilitan pada motor diperlihatkan pada Persamaan (1) sebagai berikut:

$$
\mathrm{T}_{\mathrm{t}}=\mathrm{T}_{\mathrm{c}}+\left(\mathrm{R}_{\mathrm{h}}-\mathrm{R}_{\mathrm{c}}\right) / \mathrm{R}_{\mathrm{c}} \times\left(\mathrm{T}_{\mathrm{c}}+234,5\right)
$$

dengan:

$\mathrm{T}_{\mathrm{t}}=$ temperatur lilitan total $\left({ }^{\circ} \mathrm{C}\right)$

$\mathrm{T}_{\mathrm{c}}=$ temperatur saat motor dingin $\left({ }^{\circ} \mathrm{C}\right)$

$\mathrm{R}_{\mathrm{h}}=$ hambatan motor pada saat panas $(\Omega)$

$\mathrm{R}_{\mathrm{c}}=$ hambatan motor saat dingin $(\Omega)$

$234.5=$ Konstanta lilitan tembaga

Penyebab kenaikan temperatur motor listrik seperti misalnya :

1. overcurrent (bisa disebabkan karena overload, undervoltage, overvoltage, tegangan fasa tak seimbang, harmonik, atau short circuit)

2. broken rotor bar (untuk jenis rotor sangkar)

3. short pada laminasi inti stator (stator core)

4. masalah mekanis (pendinginan kurang, pelumasan kurang, misalignment)

\section{METODE}

\section{Perancangan Sistem Monitoring dan Analisis Temperatur Motor Listrik}

Peralatan sistem monitoring dan analisis temperatur motor listrik direncanakan terdiri dari beberapa rangkaian diantaranya adalah komputer, expansion card (interface), data terminal, ADC (Analog to Digital Converter), sensor temperatur, penguat sensor, alarm dan lampu Indikator. Perangkat keras Gambar 1. menunjukkan diagram blok alat monitoring dan analisis temperatur motor listrik berbasis Komputer ${ }^{[4]}$. 


\section{Catu Daya}

Catu daya menggunakan transformator step down dari tegangan bolak-balik 220 Volt menjadi 15 Volt dengan CT (Center Tap). Tegangan searah didapatkan dari keluaran regulator tegangan menggunakan IC LM 7815, LM 7915 dan LM 7805. Keluaran catu daya berupa tegangan +5 Volt yang digunakan untuk suplai ADC dan kartu antar muka serial ke komputer, sedangkan tegangan +15 Volt dan -15 Volt digunakan untuk suplai penguat sensor. Catu daya selengkapnya dapat dilihat pada Gambar 2.

\section{Penguat Relay}

Rangkaian penguat relay menggunakan penguat Darlington yang terdiri dari dua transistor NPN yang dirangkai secara bertingkat yang berfungsi untuk menguatkan arus.

Penguat ini diperlukannya karena keluaran dari port antarmuka PPI 8255 belum cukup untuk menggerakkan relay. Penguat relay ini digunakan untuk mengaktifkan alarm dan lampu indikator. Gambar penguat rele selengkapnya terlihat pada Gambar 3.

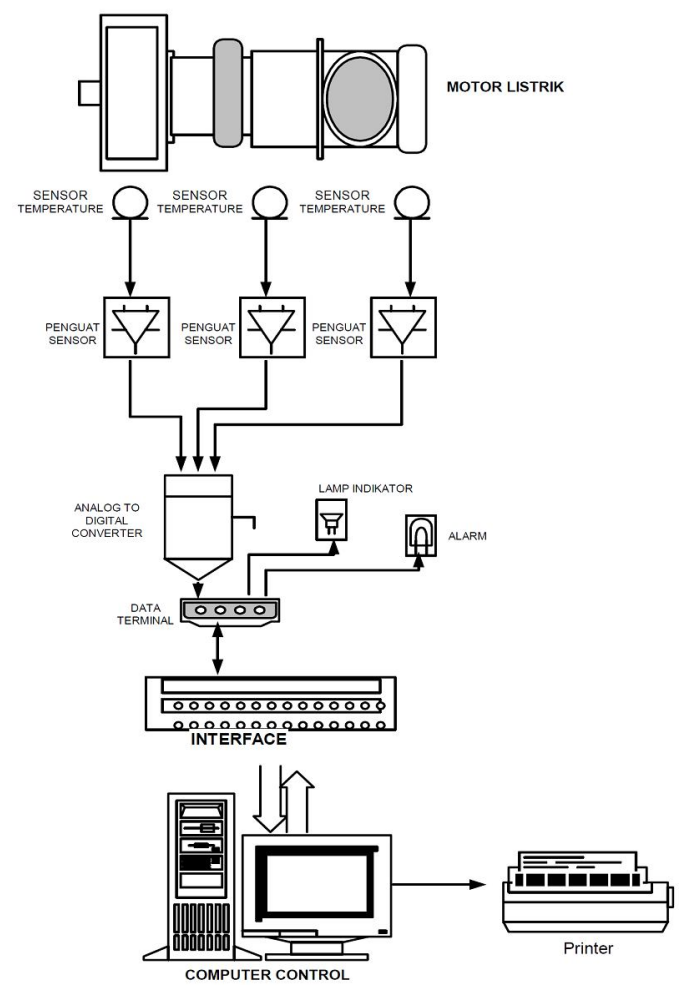

Gambar 1. Diagram Blok Alat Monitoring dan Analisis Temperatur Motor Listrik Berbasis Computer 


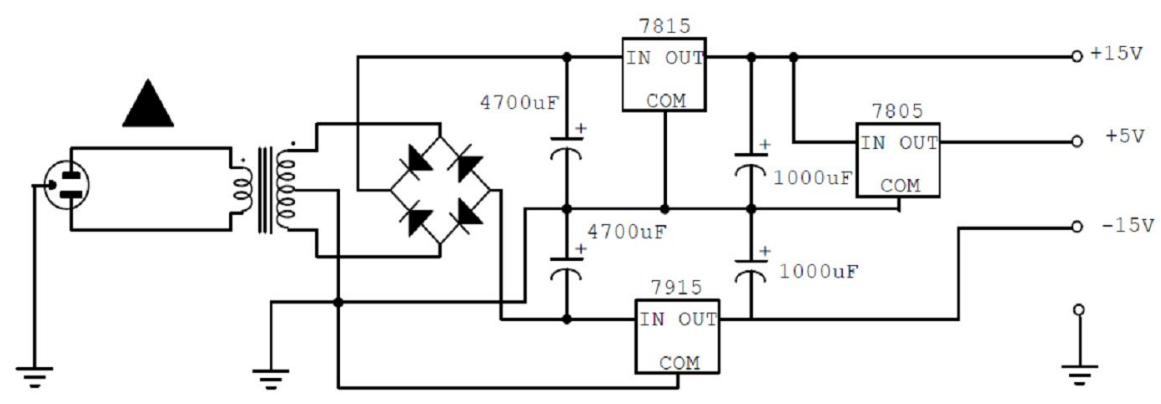

Gambar 2. Rangkaian Catu Daya

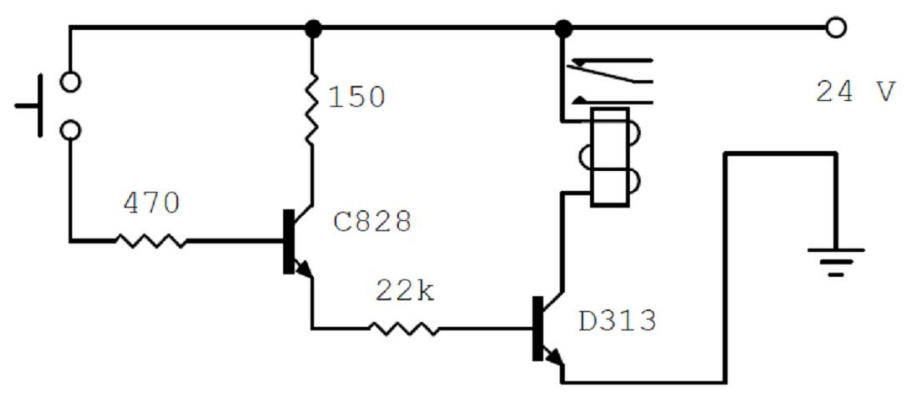

Gambar 3. Ragkaian Penguat Relay

\section{Sensor Temperatur}

Sensor temperatur yang digunakan memakai rangkaian IC sensor LM 35. Sensor ini dapat mengidentifikasikan temperatur pada motor dimana output tegangan keluaran sangat linear berpadanan dengan perubahan temperatur. Sensor ini berfungsi sebagai pengubah dari besaran fisis temperatur ke besaran tegangan yang memiliki koefisien sebesar $10 \mathrm{mV} /{ }^{0} \mathrm{C}$ yang berarti bahwa kenaikan temperatur $1^{0} \mathrm{C}$ maka akan terjadi kenaikan tegangan sebesar $10 \mathrm{mV}$. IC LM 35 ini tidak memerlukan pengkalibrasian atau penyetelan dari luar karena ketelitiannya sampai lebih kurang seperempat derajat celcius pada temperatur ruang. Jangka sensor mulai dari $-55^{\circ} \mathrm{C}$ sampai dengan $150^{\circ} \mathrm{C}$, IC LM35 penggunaannya sangat mudah, difungsikan sebagai kontrol dari indikator tampilan catu daya terbelah. Gambar bentuk dan simbol IC LM 35 sebagai sensor temperatur terlihat pada Gambar 4 , sebagai berkut: 

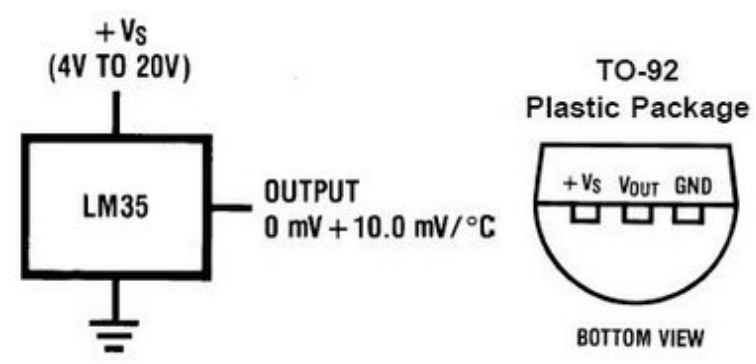

Gambar 4. Rangakaian Sensor Temperatur IC LM 35

\section{Penguat Sensor}

Penguat sensor yang digunakan memakai dua penguat inverting (membalik) menggunakan penguat operasional (OpAmp) LM 324. Pada penguat awal diletakkan setelah sensor temperatur LM 35 untuk penguatan sinyal keluaran sensor temperatur, karena sinyal tersebut masih sangat lemah. Setelah dikuatkan sekali menggunakan penguat membalik maka selanjutnya dimasukkan ke penguat Membalik lagi menggunakan penguat operasional (OpAmp) LM 324. Rangkaian penguat sensor terlihat pada Gambar 5. Keluaran penguat ini kemudian dimasukkan ke ADC sebagai masukkan. Penguat ini diperlukan agar tegangan hasil keluaran dapat disesuaikan dengan tegangan masuk ADC.

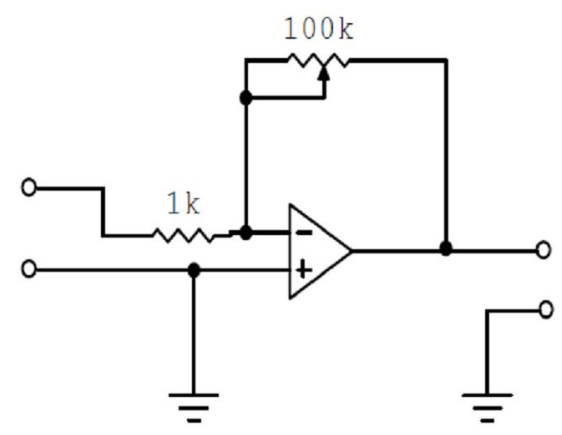

Gambar 5. Rangkaian Penguat Sensor Temperatur

\section{Antarmuka Komputer (Computer interface)}

Rangkaian antar muka komputer menggunakan koneksi serial RS 232 dengan kendali mikrokontroler dan PPI 8255 dalam penelitian ini disebut sebagai PC Link Serial. Antarmuka komputer ini digunakan untuk penghubung antara keluaran ADC dari rangkaian sensor temperatur yang akan dibaca oleh komputer. Disamping itu untuk media penyambung keluaran hasil perhitungan komputer untuk mengendalikan relay yang menghubungkan 
alarm dan lampu indikator. Komponen antarmuka mikrokontroler terdiri dari 2 port input output yang masing-masing 8 bit sedangkan PPI 8255 terdiri dari 3 port input output masing-masing 8 bit. Proses dekoder alamat (address decoder) dan kontrol ADC dilakukan oleh port PPI yang diatur oleh komputer.

PC-Link SERIAL PPI merupakan pengendali 40 bit jalur input output melalui antarmuka UART RS-232 yang dapat dihubungkan ke komputer secara langsung. Dalam penggunaan dari UART SERIAL PPI dikenal adanya Protocol Layer. UART Protocol Layer adalah lapisan yang dipergunakan untuk mengatur semua lalu lintas data dan sudah tersusun sesuai kegunaan menjadi paket. Rangkaian selengkapnya dari kartu antarmuka PPI 8255 dapat dilihat pada Gambar 6.

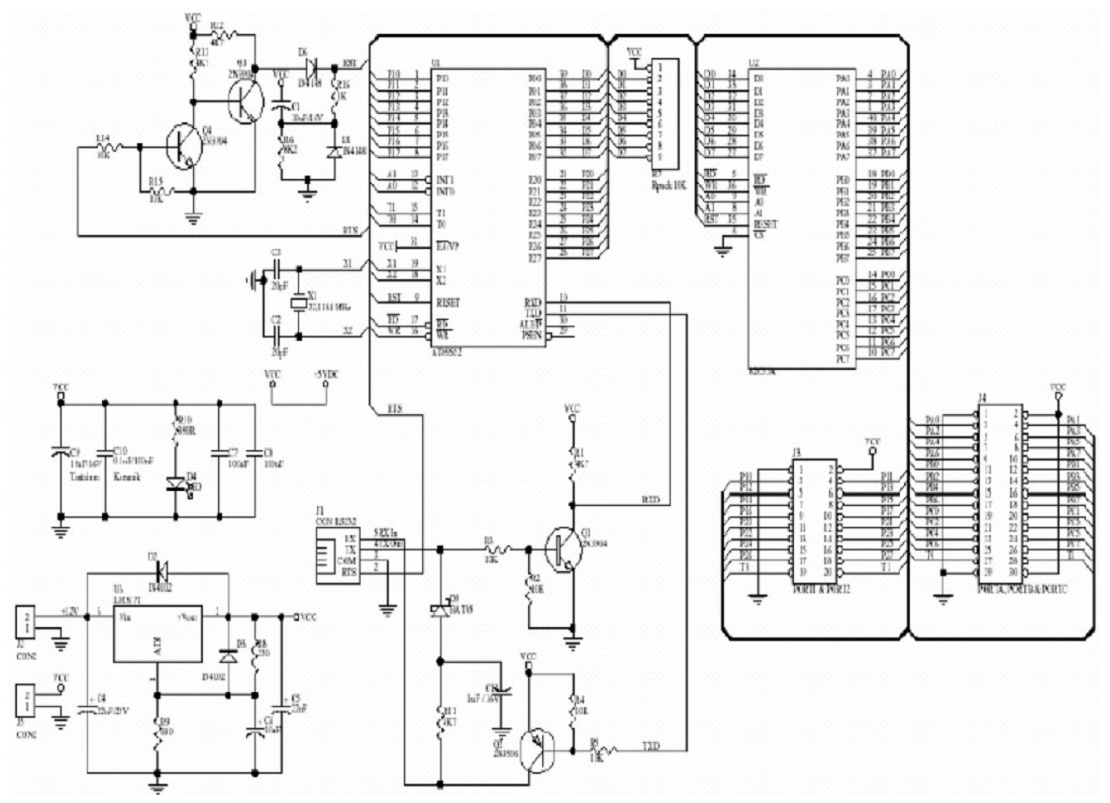

Gambar 6. Rangkaian Lengkap dari Kartu Antarmuka PC Link Serial Menggunakan Mikrokontroler dan PPI 8255

\section{Rangkaian ADC 0809}

Rangkaian ADC digunakan untuk mengkonversi tegangan analog hasil dari masing-masing sensor temperatur menjadi data digital untuk dimasukkan dalam antarmuka mikrokontroler dan PPI 8255 dan selanjutnya dibaca oleh komputer melalui data serial RS 232. Data masukan sensor ini nantinya akan diproses dalam komputer baik untuk proses monitoring, perekamam maupun proses analisis. Penelitian ini menggunakan ADC 0809 yang merupakan jenis pendekatan berurutan. ADC jenis pendekatan berurutan merupakan ADC 
yang paling banyak digunakan. Hal ini dikarenakan kemampuannya dalam memberikan pressisi yang baik untuk suatu pemakaian yang luas dengan biaya yang murah.

ADC 0809 memiliki 8 masukan, namun pada penelitian ini hanya digunakan 3 masukan yaitu untuk masukan dari sensor temperatur arah sumbu $\mathrm{X}$, temperatur arah sumbu $\mathrm{Y}$, temperatur arah sumbu $\mathrm{Z}$. Keluaran digital dari ADC 0809 adalah 8 bit yang mempunyai resolusi sebesar 256 langkah. Sistem operasi yang digunakan dalam pemakaian ADC ini adalah sistem free running mode yaitu proses konversi dilakukan secara kontinyu kapanpun saat terdapat masukan tanpa harus mendapat sinyal kendali mode operasi sehingga komputer siap melakukan pembacaan sewaktu-waktu. Rangkaian lengkap dari perangkat ADC 0809 tersebut dapat dilihat pada Gambar 7.

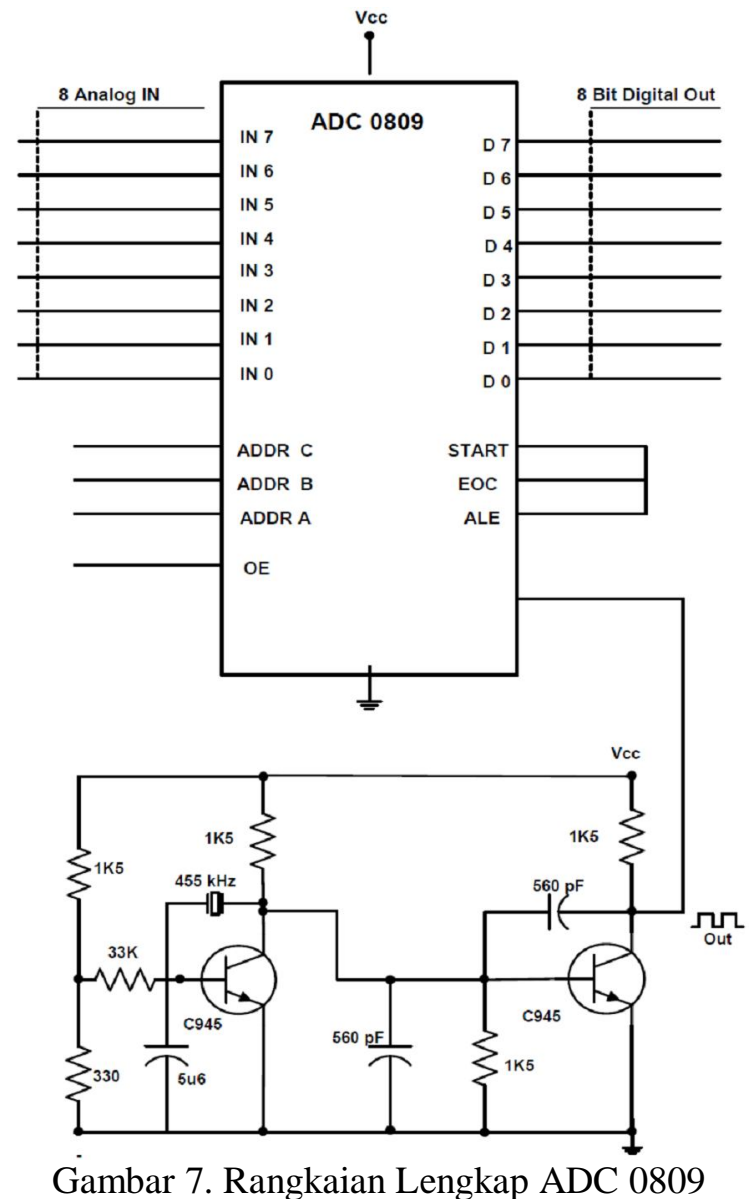

Gambar 8. menunjukkan diagram alur dari rencana program yang akan digunakan dalam sistem monitoring dan analisis temperatur motor listrik 
berbasis komputer tersebut. Diagram alur program meliputi sistem pilihan pada menu tampilan, pembacaan 3 unit sensor temperatur dari motor yang terdiri dari temperatur sensor $\mathrm{A}, \mathrm{B}$ dan $\mathrm{C}$.

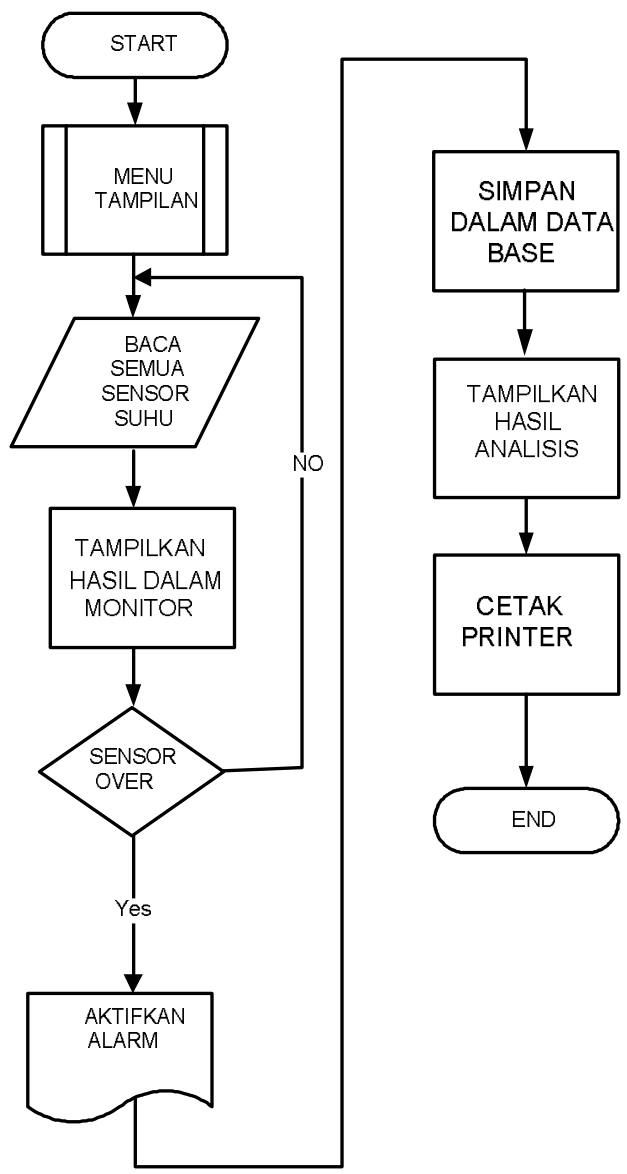

Gambar 8. Diagram Alur Program Monitoring dan Analisis Temperatur Motor Listrik Berbasis Komputer

Hasil pembacaan temperatur dari sensor tersebut dapat ditampilkan secara real time dan digunakan untuk keperluan analisis data. Apabila temperatur menunjukkan abnormal pada salah satu sensor atau keduanya maka komputer akan mengaktifkan alarm dan lampu indikator. Selain dapat ditampilkan data temperatur tersebut juga dapat direkam dalam data base yang nantinya dapat digunakan untuk keperluan analisis data untuk laporan harian, mingguan atau bulanan. Sebelum perencanaan program monitoring berikut akan disampaikan program rutin yang digunakan dalam pengaturan antarmuka komputer menggunakan PC Link Serial. 


\section{HASIL DAN PEMBAHASAN}

Setelah melakukan pembuatan dari alat monitoring, maka selanjutnya dilakukan pengujian masing-masing bagian dan setelah dicapai hasil yang baik dilanjutkan pengujian secara keseluruhan. Pengujian meliputi pengujian sensor temperatur, rangkaian penguat sensor, rangkaian ADC dan sistem interfacing monitoring temperatur dengan komputer.

Pengujian sensor temperatur dan penguatnya ini dimaksudkan untuk mengetahui karakteristik dari sensor tersebut. Pengujian dilakukan dengan menyambungkan sensor ke masukan penguat sensor ke keluaran dimasukkan ke ADC kemudian data ADC dibaca di komputer. Tabel 2 menunjukkan perbandingan antara masukan temperatur dan keluaran data digital ADC.

Tabel 2 Perbandingan Masukan Temperatur dan Keluaran Data Digital ADC

\begin{tabular}{ccc}
\hline No & Data Digital & Temperatur Termometer $\left({ }^{\circ} \mathrm{C}\right)$ \\
\hline 1 & 86 & 28 \\
2 & 97 & 35 \\
3 & 110 & 50 \\
4 & 123 & 63 \\
5 & 137 & 74 \\
6 & 138 & 88 \\
7 & 149 & 101 \\
\hline
\end{tabular}

Hasil percobaan tersebut kemudian dibandingkan dan dibuat grafik. Hasil pengujian sensor terlihat pada Tabel 2 dan Grafik perbandingan antara masukan dan keluaran terlihat pada Gambar 9.

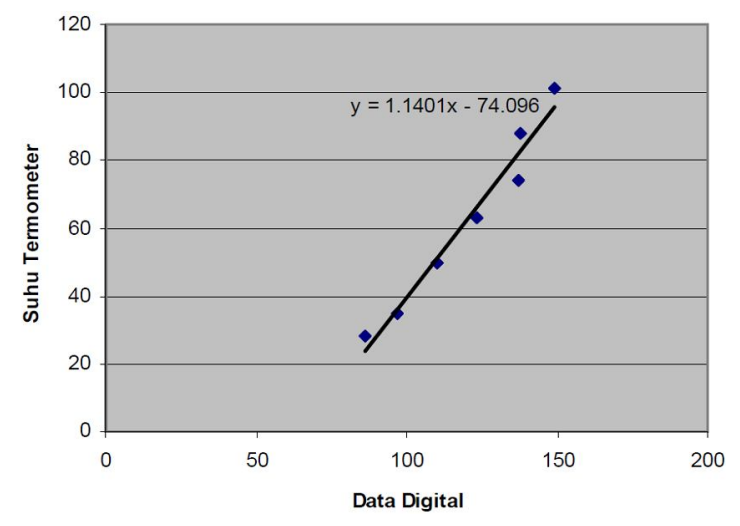

Gambar 9. Perbandingan Antara Masukan Temperatur dan Keluaran Data Digital 
Hasil pengujian penguat sensor terlihat bahwa perbandingan masukan dan keluaran dari penguat sensor menunjukkan kecenderungan linier. Setiap kenaikan temperatur termomoter yang berasal dari sumber panas yaitu solder maka sensor temperatur dan penguat sampai ADC menunjukkan respon kenaikan data digital juga. Apabila dibuat regresi liniernya maka akan didapatkan persamaan seperti pada Gambar 9. Hal tersebut sangat penting untuk mengetahui unjuk kerja sensor dan penguatnya.

Percobaan selanjutnya adalah percobaan seluruh alat dengan basis komputer. Hasil percobaan di perlihatkan pada Gambar 10. Dari hasil percobaan dapat diketahui bahwa masing masing sensor temperatur baik sensor $\mathrm{A}, \mathrm{B}$ dan $\mathrm{C}$ telah dapat bekerja dengan baik. Pada setiap kenaikan temperatur sensor motor, sensor dapat merespon kenaikan tersebut dengan ditunjukkannya pada tampilan program komputer. Warna merah pada tampilan program menunjukkan bahwa temperatur telah mencapai di atas $100^{\circ} \mathrm{C}$.

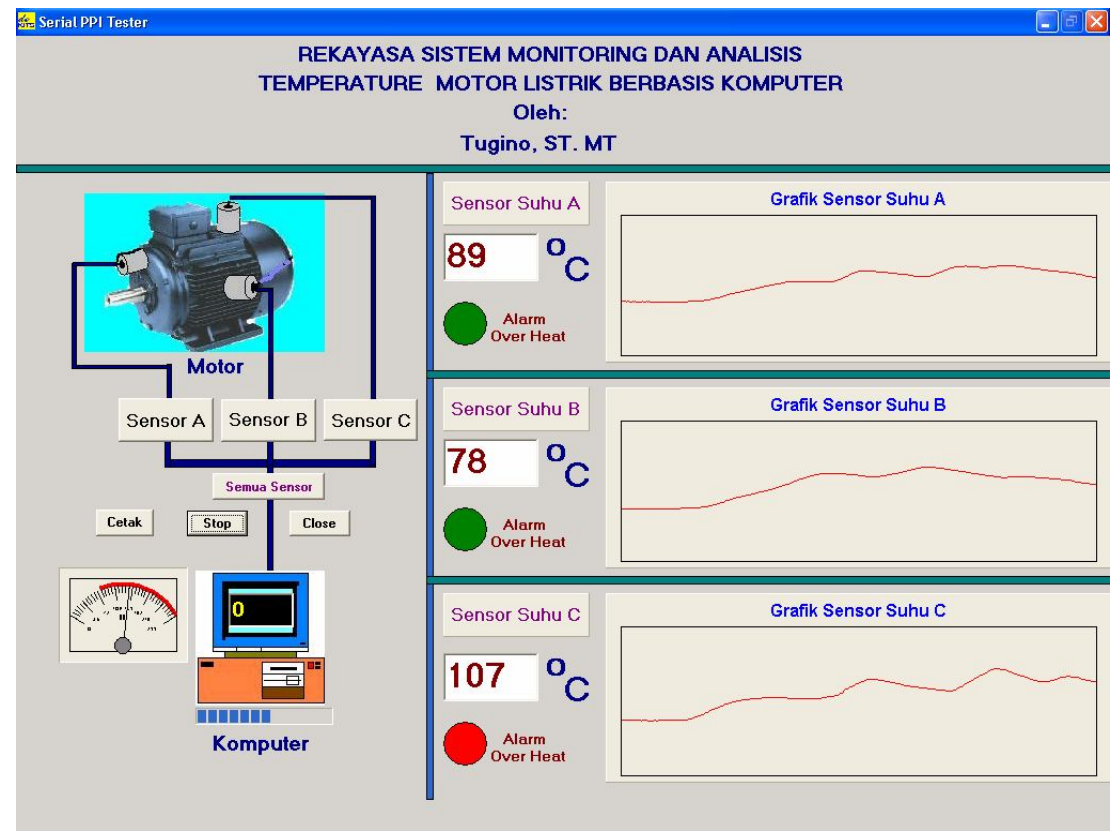

Gambar 10. Pengukuran Gabungan Sensor Temperatur A, B dan C

Dalam program telah dibuat bahwa apabila temperatur mencapai di atas $100^{\circ} \mathrm{C}$ maka alarm akan berbunyi dan tanda merah pada tampilan akan menyala. Hal ini dimaksudkan agar ada peringatan saat temperatur mencapai tinggi. Batas alarm yang menandakan temperatur tinggi dapat disetting ulang dengan merubah program. 


\section{KESIMPULAN}

1. Setelah melakukan perancangan, pembuatan dan pengujian dari alat monitoring temperatur motor listrik berbasis komputer maka didapat bahwa alat telah dapat bekerja sesuai dengan yang diinginkan.

2. Pengujian temperatur motor yang dilakukan diantaranya saat motor tanpa beban, motor berbeban seimbang dan berbeban tidak seimbang. Pada pengujian terlihat bahwa alat monitoring temperatur akan dapat mendeteksi jika terdapat kejanggalan pada motor yang akan menyebabkan kenaikan temperatur, jika kenaikan tersebut melebihi batas yang telah diseting maka alat akan menyalakan alarm dan lampu tanda bahaya.

3. Hasil dari penelitian ini dapat digunakan untuk membantu mendeteksi secara dini terjadinya kerusakan awal pada motor listrik yang dapat menyebabkan pola temperatur yang cenderung naik dan tidak stabil, sehingga dapat medukung program pemeliharaan pada motor listrik.

\section{DAFTAR PUSTAKA}

1. PETRUZELLA, F.D., 2001, Elektronik Industri, ANDI, Yogyakarta.

2. THERAJA, B.L., 1981,Hand Book of Electrical Engineering, Mc Graw Hill, New Dhelhi.

3. TUGINO, 1994, Pengendalian Kecepatan Putar Motor Arus Searah dengan Pengaturan Tegangan Berbasis Komputer, Skripsi, STTNAS, Yogyakarta.

4. WOLFGANG, L., 1989, Pengukuran Pengendalian dan Pengaturan dengan PC, Elek Media Komputindo, Jakarta. 